\title{
Paget's Disease of Bone in Patients under 40 Years
}

\section{Two case reports and review of the literature}

Kaouther Maatallah, "Dorra Ben Nessib, Emna Labbène, Hanene Ferjani, Mouna Bouaziz, Dhia Kaffel, Wafa Hamdi

$$
\text { مرض باجيت العظام عند المرضى الذين تقل أعمارهم عن } 40 \text { عامًا }
$$

كوثر معطي اله، درة بالنصيب، آمنة لبان، حنان فرجاني، منى بوعزيز، ضياء القفال، وفاء الحامدي

\begin{abstract}
ABSTRAC T: Paget's disease of bone (PDB) is a focal disorder of accelerated skeletal remodelling that is uncommon in patients under the age of 40 years; it is more prevalent in older individuals. We report two cases of PDB diagnosed in early adulthood at the Mohamed Kassab Institute of Orthopedics, La Manouba, Tunisia. The first case was a 35 -year-old male patient who presented in 2011 with a seven-month history of hip pain. The second case was a 39-year-old female patient who presented 2014 with chronic lower back pain. The PDB diagnosis was confirmed with clinical, biological and radiological investigations. Both patients were doing well on follow-up. Some previous cases have been reported in the literature, differing from the presented cases in some aspects; data of PDB features at differing ages is still insufficient. Early recognition of this clinical entity in young patients is important as early treatment can affect the progression of the disease.
\end{abstract}

Keywords: Paget's Disease of Bone; Young Adults; Diagnosis; Case Report; Tunisia.

الملخص: مرض بـاجيت العظام هـو اضطراب محوري في تسارع إعادة تشكيل الهيكل العظمي وهو أمر غير شائع في المرضى الذئ الذين تقل

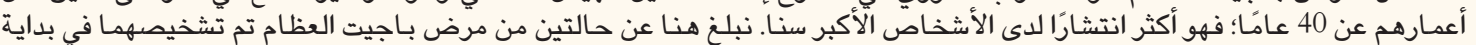

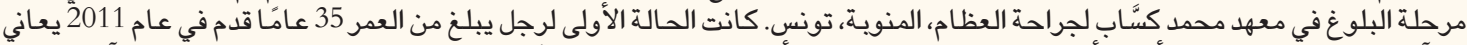

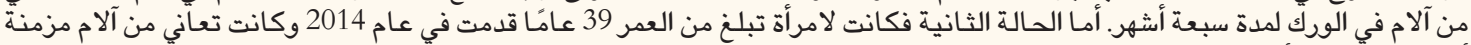

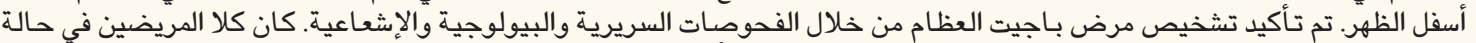

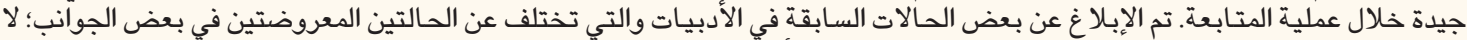

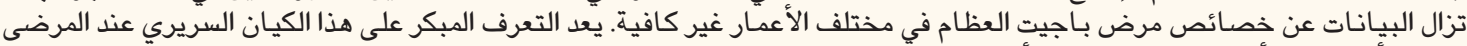

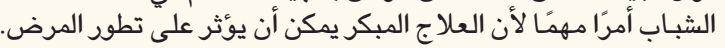

الكلمات المفتاحية: مرض باجيت العظام؛ شباب بالغين؛ تشخيص؛ تقرير حالة؛ تونس.

$\mathrm{P}$ AGET'S DISEASE OF BONE (PDB) IS A FOCAL disorder of accelerated skeletal remodelling that can involve a single bone (monostotic) or multiple bones (polyostotic). The resulting anomalous structure of the bone is responsible for pain, deformity and skeletal fragility. ${ }^{1}$ PDB is uncommon under the age of 40 years and its prevalence increases with age. ${ }^{2}$ Herein, we report two cases of PDB diagnosed in early adulthood.

\section{Case One}

A 35-year-old North-African male patient presented to the Department of Rheumatology at the Mohamed Kassab Institute of Orthopedics, La Manouba, Tunisia, in 2011 with a seven-month history of hip pain. He had no family history of Paget's disease, cancer or other musculoskeletal disorders. On examination, he had a decreased range of motion of the left hip, associated with muscular weakness. Laboratory tests showed an elevated serum level of alkaline phosphatase (ALP) at $287 \mathrm{UI} / \mathrm{L}$ (upper limit of reference range: $130 \mathrm{UI} / \mathrm{L}$ ). Serum levels of calcium, phosphate, erythrocyte sedimentation rate (ESR) and C-reactive protein (CRP) were normal. Pelvic and left hip radiographs showed sclerosis of the head and neck of the left femur with cortical thickening and a coarse trabecular pattern [Figure 1A]. The computed tomography (CT) scan confirmed these findings [Figure 1B]. The magnetic resonance imaging (MRI) of the pelvis showed coarse trabecular thickening in low signal intensity on T1 and T2 with preservation of normal fatty bone marrow signal in between [Figure $1 \mathrm{C}$ and $\mathrm{D}$ ]. The planar scintigraphy images showed increased radiotracer uptake in the head and neck of the left femur [Figure 2]. No neurological complications were 


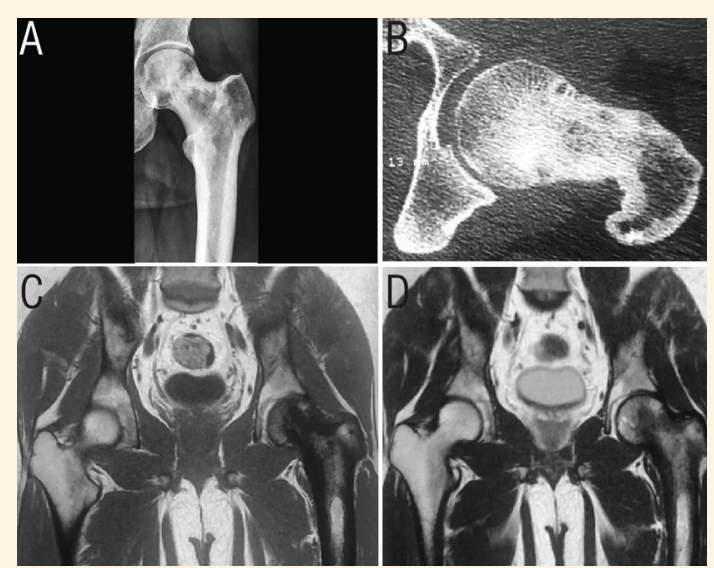

Figure 1: Anteroposterior radiograph of the left hip and coronal T2-weighted and T1-weighted magnetic resonance images of the pelvis of a 35-year-old male patient (case one). A: Axial computed tomography scan of the left hip. B: Sclerotic changes of the head and neck of the left femur with cortical thickening and coarse trabecular pattern. C: T2- and D: T1-weighted images showing coarse trabecular thickening with preservation of normal fatty bone marrow signal in-between.

detected. Given the typical radiographic findings and the absence of warning signs such as morning stiffness, deterioration in general condition and an increase in the inflammatory markers, PDB was considered as the most probable diagnosis. A course of intravenous (IV) pamidronate for three days resulted in clinical improvement and a decrease in the level of ALP to 81 UI/L. Regular six-monthly follow-ups were performed for nine years. Although the range of motion of the left hip remained reduced on examination, the patient was satisfied with the treatment results and did not report any complaint. The follow-up radiographs did not show significant changes compared to the baseline data and the blood levels of calcium, phosphorus, ALP, creatinine, ESR and CRP were within normal limits.

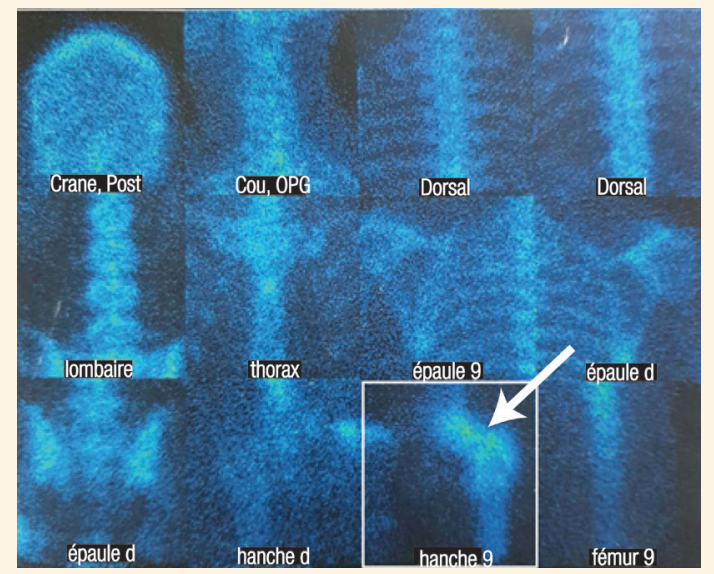

Figure 2: The technetium 99m-methyl diphosphonate planar scintigraphy images of a 35-year-old male patient (case one) showing increased radiotracer uptake in the head and neck of the left femur (arrow).

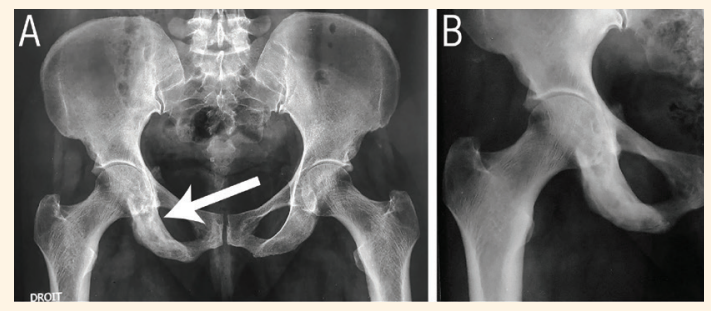

Figure 3: Anteroposterior radiograph of the pelvis (A) and the right hip (B) of a 39-year-old female patient (case two) showing enlargement and sclerosis of the right ischiopubic ramus with cortical thickening, thickening of the ilioischial line (arrow) and coarse trabecular pattern.

\section{Case Two}

A 39-year-old North-African female patient, with no family history of Paget's disease or other bone disorders, was referred to the Department of Rheumatology in 2014 for chronic lower back pain. A thorough clinical examination did not reveal any significant findings. The level of ALP was 174 UI/L. Pelvic and right hip radiographs showed enlargement and sclerosis of the right ischiopubic ramus with cortical thickening, thickening of the ilio-ischial line and a coarse trabecular pattern [Figure 3]. The bone scintigraphy revealed increased radionuclide uptake in the same region. In view of the chronicity of pain, overall well-being, normal level of calcium and typical radiographic abnormalities, the patient was diagnosed with PDB. Considering the site of PDB, it was decided to treat the patient with pamidronate $60 \mathrm{mg}$ IV infused for three consecutive days (September 2014). After an initial clinical and biological improvement, a flare-up was observed after four years. The ALP level increased from $116 \mathrm{UI} / \mathrm{L}$ (January 2018) to $168 \mathrm{UI} / \mathrm{L}$ (February 2019). Therefore, zoledronic acid infusion was administered after which the patient's clinical condition and biochemical markers began to improve. In the last follow-up visit (December 2019), she had no pain. Laboratory tests were within the reference ranges and the ALP level decreased from $168 \mathrm{UI} / \mathrm{L}$ to $61 \mathrm{UI} / \mathrm{L}$. The last follow-up radiographs were comparable to the initial findings.

\section{Discussion}

PDB is a focal disorder initiated by overactive osteoclastic bone resorption followed by a compensatory increase in osteoblastic new bone formation. Typically, it is more prevalent in older individuals and prevalence increases with advancing age. ${ }^{3}$

We report two cases of $\mathrm{PDB}$ in patients under the age of 40 years. Considering the typical radiographic appearance of Paget's disease on the one hand, and 


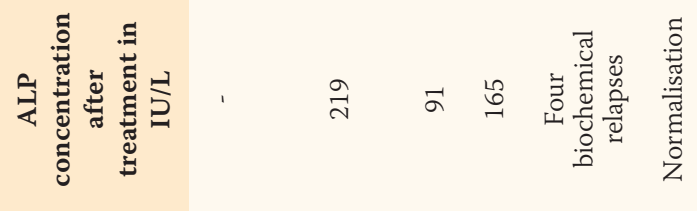

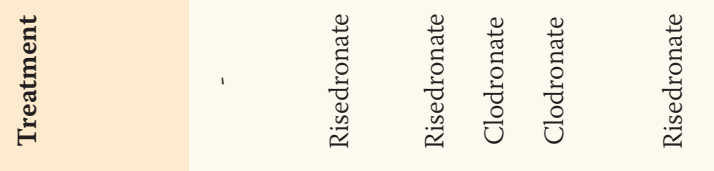

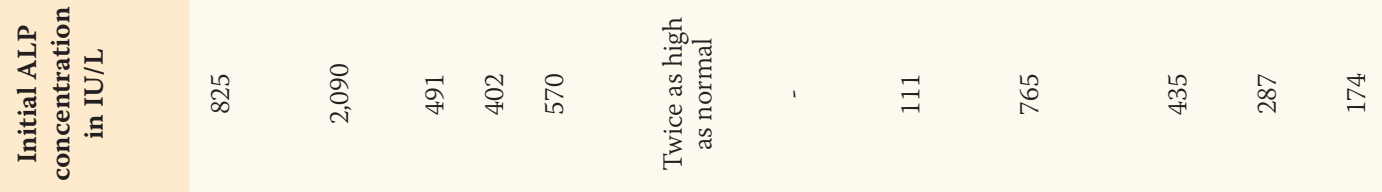

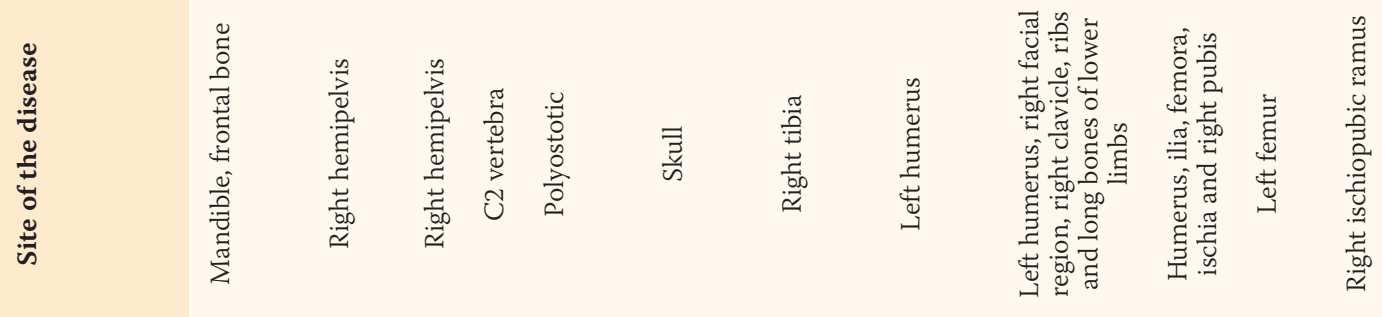

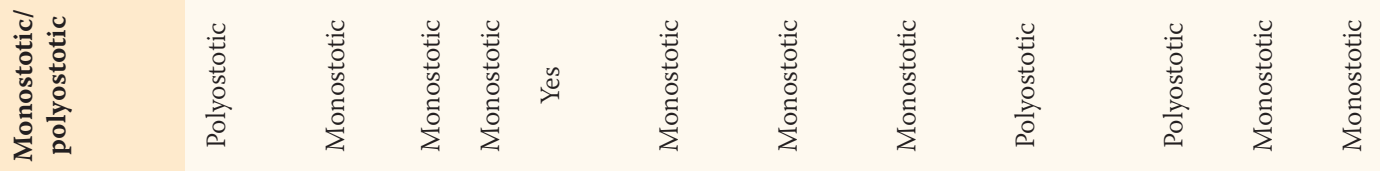

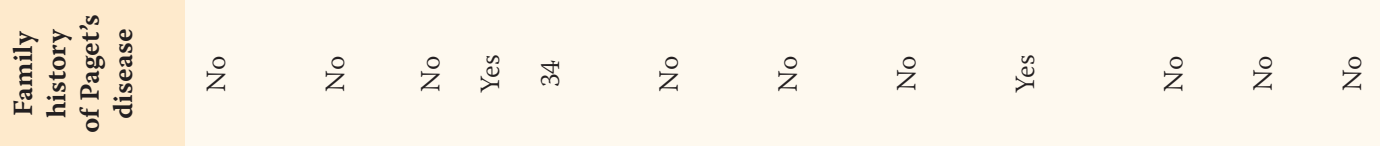

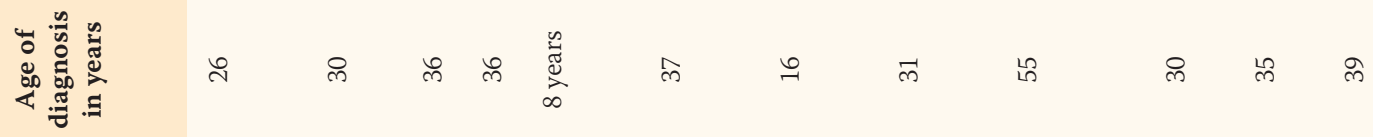

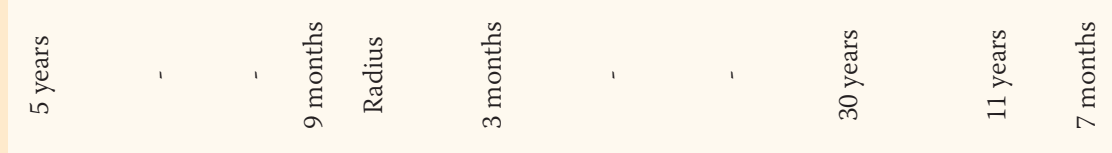

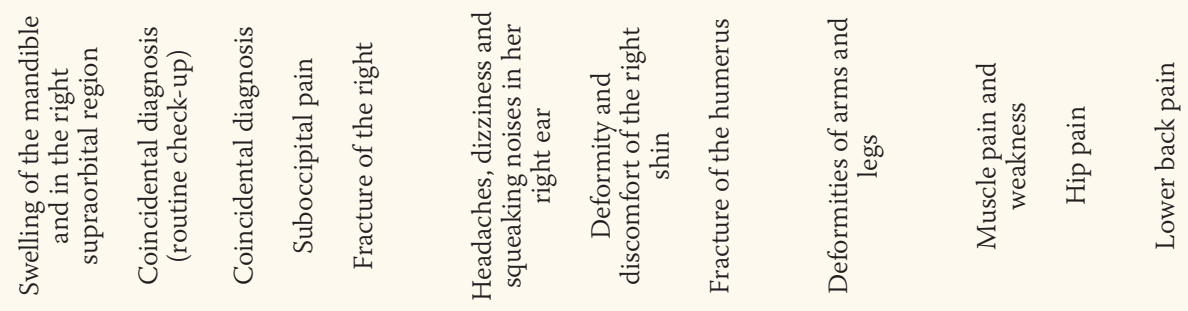

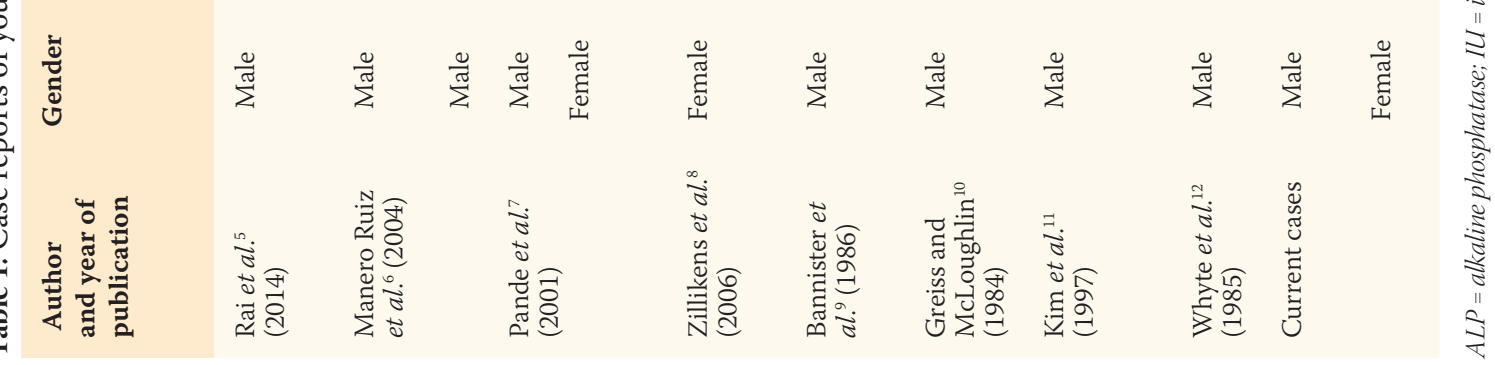


Table 2: Previous studies investigating Paget's disease of bone in young adults ${ }^{2,14}$

$\begin{array}{lcc}\text { Author and year of publication } & \text { Choma et al. }{ }^{2}(2004) & \text { Holgado } \text { et al. } .^{14} \text { (2005) } \\ \text { Location } & \text { USA } & \text { Catalonia, Spain } \\ \text { Sample size } & 521 & 314 \\ \text { Patients under } 40(\%) & 52(10) & 18(5.7) \\ \text { Features of the younger age group } & - & 35.4 \pm 5.5(18-40) \\ \text { Mean age in years } \pm \text { SD (range) } & - & 1: 1 \\ \text { Gender ratio } & - & 3(17) \\ \text { Family history } & - \text { Pain }(44) & - \text { Incidental diagnosis }(44) \\ \text { First presentation (frequency) } & 27(53) & - \text { Pain (11) } \\ & 37(71) & - \\ \text { Axial involvement } & \text { Tibia } & - \\ \text { Appendicular involvement } & & - \text { Pelvis (61) } \\ \text { Most commonly affected site } & 37(71) & - \text { Skull (45) } \\ \text { (frequency) } & 0(0) & 5(27.7) \\ \text { Monostotic involvement } & & 0(0) \\ \text { Associated malignancy } & & \end{array}$

the absence of warning signs (deterioration of the general condition, increased inflammatory markers or hypercalcaemia) on the other hand, a biopsy was not performed on our two patients. In fact, mixed pictures of lysis and sclerosis lead to the distinctive radiographic appearance of Paget's disease and biopsy is rarely required to establish the diagnosis. ${ }^{4}$ In addition, given the positive outcomes demonstrated both clinically and biologically and the long follow-up periods, malignant bone tumours were excluded.

There have been some cases of PDB in young adults reported in the literature [Table 1]..$^{5-12}$ The preponderance of males noted among these cases agreed with data related to older patients. ${ }^{13}$ As in the elderly, the most common clinical presentation includes pain, bone deformities and fractures; the majority of patients have monostotic involvement. ${ }^{13}$ According to a recent systematic review of 332 cases of PDB of all ages, the ALP levels were 10 times higher than the normal limit in the majority of patients with a mean value of $1200.8 \mathrm{UI} / \mathrm{L} .^{13}$ Therefore, it seems that the initial values of ALP are lower in young patients.

Data provided by medical literature comparing PDB features according to age is still insufficient. To the best of the authors' knowledge, two retrospective studies which included a large number of patients with PDB have compared a younger group of patients (under 40) to an older group [Table 2]. ${ }^{2,14}$ Choma et al. found that the younger group had less axial but more monostotic involvement. ${ }^{2}$ Despite the relative rarity of Paget's disease in African-American patients, a significant number of African-Americans was reported in the younger group. ${ }^{2}$

Conversely, in a Catalonian retrospective study conducted by Holgado et al., PDB diagnosed in early adult life was found to be more extensive (predominance of polyostotic forms and a higher Coutris extension index) but less active (Renier's activity index). ${ }^{14}$ The ALP values were found to be significantly higher than in patients diagnosed after age 40. These results, contrasting with previous data reported by Choma et al., may be explained by the limited number of young patients $(n=18)$ and the absence of male preponderance (50\%). ${ }^{2,14}$ In fact, the number of affected bones and the values of ALP levels were found to be higher in women. ${ }^{14}$

The low risk of malignancy in younger patients was noted in both studies and in previous studies as well..$^{2,14-16}$ This may be attributable to early diagnosis and prompt treatment. By counteracting bone catabolism, the bisphosphonates remain the cornerstone of medical management. ${ }^{17}$ In a retrospective study conducted by Zati and Bilotta, 18 out of 119 patients with PDB developed sarcoma. ${ }^{18}$ Considering the absence of sarcoma developing in patients treated with bisphosphonates, it has been suggested that this therapeutic option may potentially have a preventative effect on the degeneration of PBD. In fact, the inhibitory effect of bisphosphonates on osteosarcomatous cells has been previously demonstrated in vitro. ${ }^{19,20}$ Further investigations are required to confirm or refute this finding. 
In summary, several 'red flags' should be noted as early predictors of the PDB diagnosis in order to initiate prompt treatment: family history of PDB, fractures without an apparent cause, an even moderate increase in ALP levels and MRI images showing preservation of normal fatty bone marrow signal. Several unanswered questions remain regarding the natural history of this disease as it appears in younger patients. The role of heredity requires further investigation; it has been known for many years that PDB sometimes occurs in more than one member of a family. Genealogical studies support a hereditary disposition for PDB, perhaps mediated by an immune deficiency. ${ }^{11}$ Another hypothesis has been advanced by Renier and Audran who investigated the progression of Pagetic lesions over the years. ${ }^{21}$ They found that bone lesions could have started before the age of 30 in $64 \%$ of patients diagnosed with this disease at the age of 70 or older. The authors concluded that PBD may have started and gone unnoticed in early adult life and was then first noticed at a later age. ${ }^{21}$

\section{Conclusion}

Paget's disease may be a disease of young adults that remains undiagnosed until later in life. Early treatment of these patients can affect the progression of the disease, hence early diagnosis is very important. Therefore, an even moderate increase in ALP levels associated with early radiological lesions should be taken into consideration.

\section{References}

1. Lyles KW, Siris ES, Singer FR, Meunier PJ. A clinical approach to diagnosis and management of Paget's disease of bone. J Bone Miner Res 2001; 16:1379-87. https://doi.org/10.1359/jbmr.2 001.16.8.1379.

2. Choma TJ, Kuklo TR, Islinger RB, Murphey MD, Temple HT. Paget's disease of bone in patients younger than 40 years. Clin Orthop Relat Res 2004;202-4. https://doi.org/10.1097/000 03086-200401000-00033.

3. Morales-Piga AA, Rey-Rey JS, Corres-González J, GarcíaSagredo JM, López-Abente G. Frequency and characteristics of familial aggregation of Paget's disease of bone. J Bone Miner Res 1995; 10:663-70. https://doi.org/10.1002/jbmr.5650100421.

4. Cundy T. Paget's disease of bone. Metabolism 2018; 80:5-14. https://doi.org/10.1016/j.metabol.2017.06.010.

5. Rai H, Pai SM, Dayakar A, Javagal V. A rare incident of Paget's disease of bone in early adult life. J Oral Maxillofac Pathol 2014; 18:S147-50. https://doi.org/10.4103/0973-029X.141373.
6. Manero Ruiz FJ, Urruticoechea Arana A, Medrano San Ildefonso M, Pecondón Español A. [Bone Paget's disease in the young adult]. Rev Clin Esp 2004; 204:532-4. https://doi. org/10.1157/13066177.

7. Pande KC, Ashford RU, Dey A, Kayan K, McCloskey EV, Kanis JA. Atypical familial Paget's disease of bone. Joint Bone Spine 2001; 68:257-61. https://doi.org/10.1016/s1297319x(01)00267-6.

8. Zillikens MC, Ginai AZ, Pols HA. [A young woman with headaches and skull anomalies: A long road to the diagnosis 'Paget's disease']. Ned Tijdschr Geneeskd 2006; 150:2150-4.

9. Bannister P, Roberts M, Sheridan P. Recurrent hypercalcaemia in a young man with mono-ostotic Paget's disease. Postgrad Med J 1986; 62:481-3. https://doi.org/10.1136/pgmj.62.728.481.

10. Greiss M, McLoughlin SJ. Pathological fracture of the humerus in a young adult with Paget's disease of bone. Injury 1984; 16:204-6. https://doi.org/10.1016/0020-1383(84)90163-3.

11. Kim GS, Kim SH, Cho JK, Park JY, Shin MJ, Shong YK, et al. Paget bone disease involving young adults in 3 generations of a Korean family. Medicine (Baltimore) 1997; 76:157-69. https:// doi.org/10.1097/00005792-199705000-00002.

12. Whyte MP, Daniels EH, Murphy WA. Osteolytic Paget's bone disease in a young man. Rapid healing with human calcitonin therapy. Am J Med 1985; 78:326-32. https://doi. org/10.1016/0002-9343(85)90444-9.

13. Wang QY, Fu SJ, Ding N, Liu SY, Chen R, Wen ZX, et al. Clinical features, diagnosis and treatment of Paget's disease of bone in mainland China: A systematic review. Rev Endocr Metab Disord 2020; 21:645-5. https://doi.org/10.1007/s11154-02009544-x.

14. Holgado S, Rotés D, Gumà M, Monfort J, Olivé A, Carbonell J, et al. Paget's disease of bone in early adult life. Ann Rheum Dis 2005; 64:306-8. https://doi.org/10.1136/ard.2004.021139.

15. Mckenna RJ, Schwinn CP, Soong KY, Higinbotham NL. Osteogenic sarcoma arising in Paget's disease. Cancer 1964; 17:42-66. https://doi.org/10.1002/1097-0142(196401)17:1<42::aidcncr2820170108>3.0.co;2-u.

16. Porretta CA, Dahlin DC, Janes JM. Sarcoma in Paget's disease of bone. J Bone Joint Surg Am 1957; 39-A:1314-29. https://doi. org/10.2106/00004623-195739060-00009.

17. Reid IR. Management of Paget's disease of bone. Osteoporos Int 2020; 31:827-37. https://doi.org/10.1007/s00198-019-05259-1.

18. Zati A, Bilotta TW. Degeneration of Paget's disease into sarcoma: Clinical and therapeutic influencing factors. Chir Organi Mov 2008; 92:33-7. https://doi.org/10.1007/s12306008-0043-6.

19. Sonnemann J, Eckervogt V, Truckenbrod B, Boos J, Winkelmann W, van Valen F. The bisphosphonate pamidronate is a potent inhibitor of human osteosarcoma cell growth in vitro. Anticancer Drugs 2001; 12:459-65. https://doi.org/10.10 97/00001813-200106000-00007.

20. Mackie PS, Fisher JL, Zhou H, Choong PF. Bisphosphonates regulate cell growth and gene expression in the UMR 106-01 clonal rat osteosarcoma cell line. Br J Cancer 2001; 84:951-8. https://doi.org/10.1054/bjoc.2000.1679.

21. Renier JC, Audran M. Progression in length and width of pagetic lesions, and estimation of age at disease onset. Rev Rhum Engl Ed 1997; 64:35-43. 